\title{
Escola e profissão docente: uma reflexão em tempos de covid-19
}

\author{
School and teaching profession: a reflection in times of covid-19 \\ Escuela y profesión docente: una reflexión en tiempos de covid-19
}

\author{
Eliane Paganini da Silva ${ }^{1}$ \\ Autor Franciele Clara Peloso ${ }^{2}$
}

\begin{abstract}
Resumo:
$\mathrm{O}$ artigo analisa o modelo escolar baseado em uma visão conteudista e como esse modelo aparece significado ou ressignificado frente a pandemia da Covid-19. Propõe-se uma análise do ensino remoto, da profissionalidade docente e da visibilidade da infância no processo educacional. A pesquisa é fruto de revisão bibliográfica (Nóvoa 2009, 2017) e de um estudo de caso com análise da prática docente no contexto de aula remota. A partir da análise empreendida, sugere-se três aspectos primordiais para pensar a superação do modelo escolar tradicional: promoção de ambientes sócios morais; práticas cooperativas e promoção da aprendizagem; tomada de consciência da identidade profissional docente com vistas à superação da desprofissionalização docente. As principais contribuições desse artigo destacam a necessidade de valorização da profissão docente, bem como a necessidade de alavancar uma formação que consiga conectar professoras/es com os contextos sociais e políticos vigentes, promotores de aprendizagens.
\end{abstract}

Palavras-chave: Profissão docente; Ensino remoto; Educação na pandemia; Infância.

\begin{abstract}
:
The article analyzes the school model based on a content view and how this model appears meaningful or resignified in the face of the Covid-19 pandemic. An analysis of remote education, teaching professionalism and the visibility of childhood in the educational process is proposed. The research is the result of a bibliographic review and a case study with analysis of teaching practice in the context of remote classes. Three main aspects are suggested to think about overcoming the traditional school model: promoting social and moral environments; cooperative practices and the promotion of learning; awareness of the teaching professional identity with a view to overcoming teacher deprofessionalizations. The main contributions of this article highlight the need to value the teaching profession, as well as the need to leverage training that can connect teachers with the current social and political contexts that promote learning.
\end{abstract}

Keywords: Teaching profession; Remote teaching; Education in the pandemic; Childhood

\section{Resumem}

\footnotetext{
${ }^{1}$ Doutora em Educação pela Unesp-Marília. Professora Adjunta da Universidade Estadual do Paraná (UnesparApucarana). Pedagoga e Professora do Programa de Pós-Graduação em Educação Inclusiva (PROFEI). E-mail: elian_ps@ @otmail.com ORCID: http://lattes.cnpq.br/5103036346581478

${ }^{2}$ Doutora em Educação pela UFSCar. Professora Adjunta do quadro docente da Universidade Tecnológica Federal do Paraná/UTFPR. Professora Permanente do Programa de Pós-Graduação em Desenvolvimento Regional - PPGDR/UTFPR -Email: fclara.15@gmail.com ORCID: http://orcid.org/0000-0002-9647-001X
} 
El artículo analiza el modelo de escuela a partir de una visión de contenido y cómo este modelo aparece significante o resignificado frente a la pandemia Covid-19. Se propone un análisis de la enseñanza a distancia, la profesionalidad docente y la visibilidad de la infancia en el proceso educativo. La investigación es el resultado de una revisión de la literatura y un estudio de caso con un análisis de la práctica docente en el contexto de las aulas remotas. Se sugieren tres aspectos clave para pensar en la superación del modelo de escuela tradicional: promoción de entornos socio-morales; prácticas cooperativas y promoción del aprendizaje; conciencia de la identidad profesional del profesorado con miras a superar la desprofesionalización del profesorado. Los principales aportes de este artículo destacan la necesidad de valorar la profesión docente, así como la necesidad de apalancar la formación que pueda conectar a los docentes con los contextos sociales y políticos actuales que promueven el aprendizaje.

Palabras clave: Profesión docente; Enseñanza remota; Educación en la pandemia; Infancia.

\section{Introdução}

Em tempos de pandemia, ainda com consequências incertas em nível global, os cenários educativos, mais especificamente a escola e por conseguinte docentes, passam por uma grande crise de identidade sobre a especificidade do ensino. Sabe-se que as preocupações da escola e de muitos docentes ainda estão atreladas ao cumprimento do currículo, que por sua vez, tem como finalidade última a avaliação. Cabe nesse contexto histórico, mais do que nunca, refletir sobre o que é necessário ensinar e aprender e como isso deve e pode ser feito.

Nóvoa $(2009,2017)$ indica em seus escritos que os professores/as têm sido engolfados de tantas exigências em relação ao currículo escolar e suas burocracias. Ressalta, ainda, que a educação escolar vem sendo desenvolvida sem grandes alterações a muito tempo. Em outras áreas, como por exemplo na medicina, na odontologia, nas engenharias, isso não ocorre e não é visto como algo produtivo, já que a atualização dos profissionais, atrelada ao contexto inovador, é aceita e ressaltada. Entretanto, com relação à educação escolar muitas vezes o que é ressaltado socialmente são as práticas conservadoras de ensino e disciplina escolar. É necessário considerar o campo teórico produzido acerca da educação e mudar o scopo da escola e de suas raízes impregnadas de uma concepção de aprendizagem em que a aula e, sobretudo, o conteúdo são os únicos atores do processo.

A pandemia exigiu que a escola, enquanto espaço físico, fosse esvaziada. No entanto, professores/as e estudantes não desistiram do ato educativo, pois continuam fazendo escola por outros meios. Nesse sentido, é importante destacar que tanto professores/as, quanto estudantes se utilizam de artefatos tecnológicos que tem acesso.

Revista Devir Educação, Lavras-MG. Edição Especial, p.409-429, Set./2021. 
Cabe sublinhar que no Brasil temos quadros de desigualdade de acesso, bem como de dificuldade de manejo dos recursos tecnológicos, sem contar que muitos dos professores/as não têm formação específica para uma prática pedagógica não presencial. Mesmo assim, algumas instituições vêm mantendo as "aulas" que ocorrem via plataformas digitais como Moodle, plataformas privadas, Google Classroom, dentre outras, e estas requerem além de um conteúdo escrito editado pelo/a professor/a, a preparação de vídeos gravados e editados anteriormente.

Outra possibilidade são os aplicativos de mensagens (em formato escrito, de vídeo e/ou imagem) (Whatsapp, Telegram, Messenger). Também há o uso de aplicativos de conversas para vídeo chamada em grupo (Skype, Zoom, Hangout, Meet, dente outros) sendo utilizados como recursos para reuniões e/ou formações dos docentes, bem como forma de interação entre os professores/as e estudantes. As escolas públicas, com distinções entre os diferentes estados da federação, procuraram desenvolver as atividades a distância contando com a gravação de aulas e em alguns casos até com a transmissão dessas por TV aberta em canais contratados.

Obviamente, que a intenção não é criticar nenhuma dessas iniciativas tendo em vista que todos procuram se organizar da melhor forma possível para possibilitar o acesso e a não interrupção das atividades escolares nesse momento. Mas cabe refletir sobre o real êxito desse empenho coletivo.

São muitas as implicações do contexto que vem sendo trilhado durante esse período. Os docentes estão sendo massacrados no processo de domínio das tecnologias digitais e organização das aulas a partir da transposição de metodologia presencial para as iniciativas remotas, bem como de outras questões que desconsideram o docente enquanto pessoa, com uma carga de trabalho maior do que a habitual. Da mesma forma merece atenção as crianças, em especial aos estudantes da Educação Infantil e primeiro ciclo do Ensino Fundamental, que tanto na rede particular quanto na pública vem de alguma forma recebendo ou tentando receber as aulas remotas. Se faz necessário analisar isso sob a ótica da criança, sob suas necessidades, seus anseios e sua condição intelectual e afetiva para o desempenhar dessa função.

Finalmente há a necessidade de refletir efetivamente sobre a possibilidade de uma mudança na/da escola. Uma mudança de olhar, de significado, de função, de identidade. Muitos perceberam após a pandemia de Covid-19, em diferentes lugares do mundo, a 
necessidade de termos sistemas políticos e sociais que presem mais pela igualdade social e financeira, pela empatia que nos torna humanos, por dar mais significado para o ser do que para o ter, pela urgência em minimizar as formas de consumo e preservar a natureza. Tais aspectos no campo educacional vêm sendo debatidos no âmbito da psicologia escolar, da sociologia educacional, da filosofia e da formação de professores/as, há tempos. Tomamos como base para essa afirmação, de forma ampla, os escritos de Freud (1997), Winnicott (1975), Piaget (2011), Freire (1996; 2008), Adorno (2003), Imbernón (2004), Nóvoa (2009, 2017), Singer (2010), Boaventura Sousa Santos (2020), dentre outros.

Frente ao exposto, este artigo objetiva problematizar e refletir sobre a necessidade de analisar o modelo escolar baseado no acúmulo de conteúdo (visão conteudista) e, como esse modelo aparece significado ou ressignificado frente a pandemia de Covid-19. Tem-se como proposta metodológica de pesquisa o estudo de caso, ancorado por uma pesquisa maior ${ }^{3}$, porém para esse artigo será considerado um recorte objetivando a análise de uma prática pedagógica específica durante as aulas remotas.

Procurou-se nesse estudo refletir sobre as seguintes questões: $O$ ensino remoto é pertinente aos alunos da Educação Infantil e Ensino Fundamental? As especificidades infantis, com seus anseios, angústias, necessidades, desejos e desenvolvimento cognitivo estão sendo considerados nesse processo? O ensino remoto possibilita a realização das atividades escolares? É necessário rever o modelo escolar baseado no acúmulo de conteúdos escolares, aulas expositivas e provas?

Para tanto, iniciamos apresentando conceitos de ensino a distância e o que vem sendo desenvolvido durante o período de distanciamento social. Na sequência, discorremos sobre aspectos relevantes à profissão docente, sua prática e levantamos alguns aspectos relativos ao reconhecimento da infância enquanto espaço/tempo de vida. Por fim, apresentamos o relato de uma prática pedagógica e promovemos uma discussão acerca do modelo escolar e suas necessidades de superação.

\section{Educação a Distância x Ensino Remoto: um olhar sobre a prática pedagógica durante a pandemia de Covid-19}

\footnotetext{
${ }^{3}$ Profissionalidade docente e seus pilares: um estudo a partir da prática pedagógica, da formação inicial e continuada", a referida pesquisa possui aprovação do comitê de ética sob o parecer n. 2.794.397, do CCAE: 2165718.4.0000.0104, submetido à Plataforma Brasil, sob responsabilidade de uma das autoras.
} 
A Educação a Distância (EaD) se constitui em uma modalidade de ensino e é essencialmente caracterizada por professores/as e estudantes estarem separados fisicamente no espaço/tempo, sendo organizada por meio das tecnologias digitais. Entretanto, é necessário se ater a outras perspectivas sobre essa modalidade.

Historicamente essa modalidade foi registrada pela primeira vez em um curso de 1728 oferecido pela Gazeta de Boston com material para ensino e tutoria por correspondência (VASCONCELOS, 2010). No Brasil, conforme Alves (2011), alguns registros podem ter se perdido, mas de acordo com os que se tem acesso, marca de 1904 um anúncio em um jornal onde se oferece profissionalização por correspondências para datilógrafos. Obviamente que na atualidade com o avanço das tecnologias de informação e comunicação (TIC) se,

[...] reavivou a prática de EaD devido a flexibilização do tempo, quebra de barreiras espaciais, emissão e recebimento instantâneo de materiais, o que permite realizar tanto as tradicionais formas mecanicistas de transmitir conteúdos, agora digitalizados e hipermidiáticos, como explorar o potencial de interatividade das TIC e desenvolver atividades à distância com base na interação e na produção de conhecimento" (ALMEIDA, 2003, p. 330).

No Brasil as bases legais foram estabelecidas juntamente a Lei de Diretrizes e Bases da Educação Nacional, n.9304/96, no decreto n. 5622, de 19 de dezembro 2005, em seu artigo primeiro, conforme segue:

Art. 1o Para os fins deste Decreto, caracteriza-se a Educação a Distância como modalidade educacional na qual a mediação didático-pedagógica nos processos de ensino e aprendizagem ocorre com a utilização de meios e tecnologias de informação e comunicação, com estudantes e professores desenvolvendo atividades educativas em lugares ou tempos diversos (BRASIL, 2005).

Tal modalidade vem sendo, desde então, muito utilizada com vistas a democratização do ensino em diferentes áreas e assim a Educação a Distância "oferece oportunidades que pelo modelo presencial seria difícil ou impossível de atingir, pois possui uma ampla abrangência e grandiosa magnitude não somente no nosso país, mas em todo o mundo”. (ALVES, 2011, p. 91).

De acordo com Almeida (2003), existem três tipos de abordagens de EaD por meio das TIC, são elas: Broadcast (basicamente para entrega de informações e materiais), 
virtualização da sala de aula presencial (transfere a sala de aula para outro espaço/tempo) e o estar junto virtual ou aprendizagem assistida por computador (explora a interatividade com uma comunicação que aproxime emissor e receptor).

Almeida (2003) afirma que colocar os estudantes em ambientes virtuais digitais não basta para que ocorram interações significativas, tampouco é possível admitir que o acesso a hipertextos e recursos midiáticos consiga alcançar a especificidade e complexidade dos processos de ensino e aprendizagem. É com essa preocupação que os ambientes digitais de aprendizagem devem ser organizados e esses ambientes contam com um planejamento adequado e com objetivos muito claros para serem alcançados. Sendo o design educacional é constantemente revisto para o andamento das atividades.

A intenção não é desqualificar as características e possibilidades dessa modalidade de ensino, mas sim refletir que tal modalidade possui estrutura própria e questões que devem ser consideradas em termos pedagógicos para atingir o objetivo de aprendizagem. Para clarificar tal ponto, transcrevemos um apontamento de Rodrigues (2011, p.72):

\begin{abstract}
A utilização das tecnologias de informação e comunicação (TIC) na EaD implica mudança de comportamento de docentes, discentes e gestores. Os primeiros têm de aprender a se articular simultaneamente em diferentes níveis de ensino, por meio dos materiais didáticos que são construídos em redes de saberes significativos. Quanto aos estudantes, cabe lhes tomar decisões sobre o andamento de seus estudos e ter iniciativa para construir suas estratégias de aprendizagem utilizando os diferentes meios midiáticos que contribuem para a interatividade. Já os gestores devem considerar a especificidade da dimensão espaço-temporal da organização do trabalho docente de um projeto de Ead, uma vez que este não pode estar pautado na forma de gestão do ensino presencial.
\end{abstract}

Nesse aspecto não se pode atribuir ao ensino não presencial, causado pelo distanciamento social, o status de EaD. Trata-se de um ensino realizado remotamente que faz parte de uma adaptação aceitável durante o contexto pandêmico. Entretanto, o que se apresenta enquanto prática pedagógica nas escolas de educação básica dificilmente se encaixaria nas prerrogativas originais da modalidade a distância.

Pode-se então aferir que as práticas pedagógicas estão se dando de forma apenas instrumental para que o currículo seja cumprido dentro do que se estabelece como ano letivo e que muitas vezes estão sendo concretizadas apenas com a transposição do que acontecia de forma presencial e, ainda, acrescidas de atividades de repetição. Nesse sentido, as premissas 
educativas em sua amplitude ficam comprometidas cumprindo-se unicamente as demandas burocráticas.

Frente ao exposto, se faz necessário refletir sobre a profissão docente e suas especificidades.

\section{Profissão docente: especificidades e precarização na atualidade}

As discussões, ao menos dos últimos trinta anos, trazem considerações a respeito da necessidade de uma redefinição da docência, vista e compreendida como uma profissão (IMBENÓN, 2004, TARDIF; LESSARD, 2014). Imbernón (2016) assinala que ser professor/a sempre foi uma tarefa complexa e assoberbante. O autor segue sua reflexão sublinhando que no imaginário social a profissão docente é considerada flexível, tranquila e que requer poucas habilidades, uma vez que o calendário escolar é marcado por feriados festivos e os dias de férias são contabilizados em escala diferenciadas em comparação à outras profissões. No entanto, basta entrar em uma sala de aula para comprovar que o trabalho docente é multifacetado e demanda uma pluralidade de saberes e domínios. Trata-se de uma profissão complexa.

Ao docente ainda é necessário conquistar maior autonomia profissional, ter o poder de realizar adequações metodológicas necessárias, vencer o ensino tradicional e tecnicista (que simplesmente transmite um conhecimento formal), perceber que o conhecimento está em constante construção e reconstrução (assim como ele professor/a deveria estar), analisar e se conscientizar de seu compromisso político, ético e moral. Este se constitui em um panorama de incerteza e mudança, mas obviamente nunca houve, na história recente, um panorama que trouxesse tantos desafios, incertezas e mudanças (momentâneas ou não) para o contexto escolar e, por consequência, para a profissão docente.

Entende-se, assim como Freire (1996), que a docência só existe na relação estabelecida entre o educador, o educando e o mundo vivido. A condição de tornar-se professor se estabelece em um processo, não apenas a partir de uma habilitação legal. Freire (1996; 2008) afirma que ser professora/professor envolve a consciência da sua condição em ação. Ser professor/a é uma condição permeada por nossa responsabilidade ética, política, profissional e que prepara o docente para sua ação ensinante. Nesse sentido, é um desafio ainda não alcançado "o desenvolvimento da capacidade de interação de cada pessoa com o 
resto do grupo, com seus iguais e com a comunidade que envolve a educação" (IMBERNÓN, 2004, p. 14).

Ainda, de acordo com Imbernón (2004), para haver mudanças no campo profissional docente é necessário compreender e considerar que:

[...] professor possui conhecimentos objetivos e subjetivos; a aquisição de conhecimentos por parte do professor é um processo amplo e não linear; a aquisição de conhecimentos por parte do professor é um processo complexo, adaptativo e experiencial (IMBERNÓN, 2004, p. 17).

Ora como cobrar dos docentes uma mudança tão rápida e radical em sua prática? E alguns vêm sendo cobrados profissionalmente e socialmente. Será que esse processo imputado a toque de caixa será capaz de suscitar um processo amplo de reformulação da prática e suas concepções ideológicas?

Porque os professores/as não estão sendo solicitados nesse momento a exercitar suas habilidades para pensar o currículo em curso, adaptando-o adequadamente ou ainda a planejar seus programas considerando o seu público e a instituição educativa a qual se dedica? Determinações de "cima para baixo" não garantem as melhores estratégias para os processos de ensino e aprendizagem, especialmente com crianças e adolescentes.

Cabe ressaltar que, muito provavelmente, a cobrança sobre o docente que o sufoca e o adoece nos momentos normais, pode estar mais acirrada nesse período. Tem-se relatos informais de professores/as que estão sem dormir, com uma carga de trabalho três vezes maior do que tinham anteriormente, sem ter tempo de se adaptar às novas interfaces digitais. Tais ações estão atreladas à desvalorização, à desprofissionalização e a precarização do trabalho docente.

Ainda, é importante destacar que os professores/as têm sido vistos como mão de obra proletária e sendo desconsiderados(as) enquanto potencial de formação humana e, também, em sua humanidade - com suas necessidades, particularidades e identidades.

Nesse sentido, a pandemia trouxe a possibilidade de que o trabalho docente fosse percebido pelas famílias e/ou responsáveis das crianças, quando as atividades escolares passaram a acontecer de forma remota, ou seja, nas próprias residências. Ressalta-se que uma parte do público escolar apresentou dificuldades em acompanhar o ensino remoto. Várias são as causas: falta de conectividade, falta de recurso e aparelho tecnológico, falta de habilidade em lidar com as tecnologias, falta de espaço e ambiente adequado para a realização das 
atividades, crianças e famílias em vulnerabilidade e violência (moradia, alimentação, afetos precários). Em muitos casos a escola, enquanto aparelho estatal, é a única forma de assistência que chega até essas crianças, a única presença do Estado à que têm acesso. Acredita-se que a experiência do ensino remoto pode contribuir ao entendimento de que ensinar e aprender é bem mais que "assistir aula e fazer os exercícios", bem como da importância da instituição escolar para/com a sociedade.

Salvo todas essas considerações, e as crianças? Alguém de alguma forma se preocupou em questionar ou ouvir as crianças sobre esse momento, sobre suas obrigações escolares em casa? Como elas se sentem? Como gostariam que fosse? Como é ter aula na cozinha, sem seus colegas de sala?

$\mathrm{Na}$ Espanha, que vivenciou o lookdown (bloqueio total), as crianças foram lembradas enquanto "ser no mundo" após seis semanas de confinamento, como apresentam a reportagem do G1 de 26/04/2020, por exemplo:

[...] Depois de seis semanas trancadas em suas casas, as crianças espanholas começaram a sair neste domingo (26) para brincar ou passear nas ruas, num momento em que a Europa começa a flexibilizar o confinamento imposto pela pandemia de coronavírus $[\ldots](\mathrm{G} 1,2020)$.

Isso remete-nos a contextualizar que historicamente, a essência da infância é negligenciada pelos adultos, cuidadores, pelo poder público, pela escola e pela família, como lembra Peloso (2015). Desde a muito a escola desconsidera a infância, Boto (2002) evidencia a concepção de criança presente nas obras de Comenius, o qual considerava que a criança deveria deixar de sê-lo para tornar-se aluno. De acordo com Muller (2007) a escola, em sua gênese, era o lugar de preparar a criança para a vida de adulto. Esse entendimento em relação às crianças, desconsidera a infância. Será que no século XXI essa forma de compreender a escola e as crianças se transformou?

Estudos sobre a infância (ARROYO, 2008; 2012a; 2012b; SARMENTO, 2003; 2007; 2008; PELOSO, 2015 e outros) levam em consideração o conjunto de experiências vividas pelas crianças em suas realidades históricas, geográficas e sociais. Nesse sentido, Kuhlmann Junior (2007) afirma que ponderar as crianças como sujeitos históricos e sociais é se desvencilhar de discursos sobre a representação que as pessoas adultas têm das crianças e da infância e se articular um discurso que considere as crianças concretas, identificadas nas relações sociais em seus lugares históricos, geográficos, culturais, políticos e sociais e, além 
disso, reconhecê-las como produto e produtoras da história.

Sarmento (2003) menciona que dentro do conceito infância há várias infâncias. O estudioso explica que na infância global existe a desigualdade e esse dado é essencial para contemplar as distintas infâncias na contemporaneidade.

Quando se pensa na infância, é possível vislumbrar inúmeros cenários onde ela acontece, igualmente é possível identificar diversas e contraditórias situações vivenciadas pelas crianças. Por meio das mídias sociais e do cinema, podemos tomar conhecimento da situação a que infâncias e crianças estão expostas, tais como: a exploração do trabalho e a prostituição infantil, a exploração sexual, as violências físicas e psicológicas. Além disso, pode-se destacar a precariedade ou falta de acesso aos atendimentos na área da saúde, da educação pública, gratuita e de qualidade, igualmente aos bens culturais, de lazer e entretenimento, dentre outros aspectos de ordem socioeconômica e cultural.

Outrossim, também por meio das mídias sociais e do cinema, destaca-se uma parcela da população que alça grandes investimentos para o desenvolvimento da integridade física, moral e intelectual das crianças. Tais investimentos preconizam distinta concepção de infância e se materializam na forma de infraestrutura no que diz respeito à educação, à saúde, aos esportes, ao lazer e, também, à preservação de fatores socioeconômicos desses indivíduos.

Frente ao exposto, destacamos que as profissões são legitimadas pelo contexto social considerando sua função. Nesse aspecto, a legitimação da profissão docente precisa se dar a partir do reconhecimento específico de sua função na sociedade, qual seja, estar a serviço da mudança e da dignificação das pessoas - esse aspecto também passa pela compreensão do período da infância e da criança como sujeito histórico e social.

Ser um profissional da educação é ajudar a tornar as pessoas mais livres, menos dependentes de agentes que promovem desumanização. De acordo com Imbernón (1994), a profissão de ensinar tem essa obrigação intrínseca. Recentemente no Brasil assistimos posicionamentos sociais e políticos que cobram do docente exatamente o oposto, com cerceamento de ideias e pensamentos que excluem discussões ideológicas, éticas e políticas (no sentido pleno), explorando temas que deveriam ser debatidos e não serem considerados proibitivos. Vê-se a escola enquanto instituição trabalhando em prol da manutenção de modelos que impedem o desenvolvimento da autonomia, da criatividade das crianças, bem como impedem que professoras e professores coloquem em prática elementos primordiais de sua profissão, sejam eles àqueles que prezem pela humanização das pessoas.

Revista Devir Educação, Lavras-MG. Edição Especial, p.409-429, Set./2021. 
Essa reflexão traz a luz o seguinte questionamento: quando a escola passará a contribuir para essa mudança de olhar, tanto no que tange a especificidade da profissão docente, quanto à compreensão da infância e valorização das crianças? Frente a essas questões se faz necessário reflexionar sobre o modelo escolar.

\section{O modelo escolar e a necessidade de superação: reflexões a partir de um estudo de caso}

A transmissão dos conhecimentos acumulados socialmente é vista ainda hoje como a função essencial da escola, tornando-se também o centro da função docente. Entretanto, é possível indagar de que maneira essa transmissão acontece e se ainda não obedece aos modelos antigos e medievais em que o centro era a exposição oral, a memorização, em uma organização em que imperam as tradições e as submissões.

Como a literatura educacional vem apontando em diferentes campos (Política e Gestão, Psicologia, História, Sociologia, Prática Pedagógica), compreender a função da escola como meio de reprodução, bem como ser esta a função docente parece-nos um tanto quanto aligeirado. Da mesma forma considerar o papel as crianças como meras receptoras é negligenciar a capacidade dos estudantes. As relações com o conhecimento sofreram alterações desde o século XIX e continuam sofrendo a cada dia; é urgente repensar a figura do/da professor/a da atualidade e o que pretendemos para o futuro da educação.

Uma concepção de ensino-aprendizagem pautada na perspectiva dita "tradicional", como afirma Mizukami (1986), é uma prática educacional que persiste no tempo, em suas diferentes formas, e que passou a fornecer um referencial para todas as demais abordagens que a ela se seguiram. Nessa perspectiva a escola é o local, por excelência, onde acontece a apropriação do conhecimento. Na relação ensino-aprendizagem, a presença do professor é fundamental e este propicia a formação de reações estereotipadas, de automatismos denominados hábitos.

Este modelo se caracteriza pela preocupação com a variedade e quantidade de noções/conceitos/informações em detrimento à formação do pensamento reflexivo. A relação professor-aluno é vertical, sendo que um dos polos (o professor) detém o poder decisório quanto à metodologia, conteúdo, avaliação, forma de interação na aula, dentre outros. $\mathrm{O}$ aluno, por sua vez, nada mais é do que um ser passivo. 
Enquanto a escola não alterar sua percepção da infância e da docência não será possível um ambiente formador de seres humanos compromissados com o planeta em que vivem. É imprescindível que se estabeleça convivência harmônica com a natureza, bem como a execução de práticas mais humanas e de cooperação entre as pessoas que despotencialize o poder do consumo tornando-o mais consciente e em consonância com a promoção de justiça social.

É preciso que a escola assuma uma posição que ressalte o ambiente cooperativo e autônomo. Tem-se relatos de trabalhos que assumem tal perspectiva há algum tempo, mesmo sendo consideradas inciativas-piloto ou de pequena repercussão no contexto mundial. Mas é fato que tais propostas já se fazem presentes no contexto escolar.

Singer (2010) discute esses modelos de escola e esclarece que surgiram como:

[...] Resistência ao controle de vida por meio da reivindicação da autonomia das crianças sobre seus próprios corpos, suas necessidades e sua felicidade, recusando a aplicação dos mecanismos dominantes de sujeição (SINGER, 2010, p. 39).

Para a autora supracitada, as escolas democráticas consistem em uma possibilidade de socializar sem reprimir e oprimir. Além disso, é uma possibilidade de resistência no sentido de se colocar contra o modelo vigente. Atualmente existem algumas iniciativas no campo público e privado nesse sentido, com o objetivo de promover mudanças que prezem pela democratização já que tais experiências são pautadas pela égide dos princípios democráticos. (SINGER, 2010). Para pensar em um novo modelo de escola, a cooperação, as interações e o respeito mútuo entre os estudantes e professores/as é imprescindível, como ressalta Togneta (2001).

Para analisar como se materializa a escola no período da pandemia de Covid-19, apresentamos um estudo de caso, de caráter qualitativo. A breve reflexão apresentada a seguir faz parte de uma pesquisa maior já mencionada, coordenada por uma das autoras e que procura desvendar dentre outras questões as práticas autônomas e práticas que promovam autonomia entre os estudantes.

Em relação ao estudo de caso, para Chadderton; Torrance (2015), o processo de interação social, mesmo considerando contextos específicos, é importante para reconhecer e descrever o caso. Apesar de priorizar a descrição em detrimento da análise, ressaltamos que esse recurso metodológico:

Revista Devir Educação, Lavras-MG. Edição Especial, p.409-429, Set./2021. 
[...] presume que as coisas podem não ser como parecem e privilegia a investigação profunda em lugar da cobertura. [...] Quando o pesquisador de estudo de caso tem de optar entre profundidade e abrangência, a escolha recomendada é sempre a profundidade (CHADDERTON e TORRANCE, 2015, p. 91).

Os dados apresentados são de uma professora do interior do estado de São Paulo, de uma escola particular. Para esse recorte examinou-se a sua prática durante o ensino remoto, observando os arquivos enviados aos alunos, bem como seu próprio relato acerca dessa prática. Considerando a relação descrita abaixo, é possível aferir que as atividades escolares presenciais parecem terem sido replicadas para o ambiente virtual.

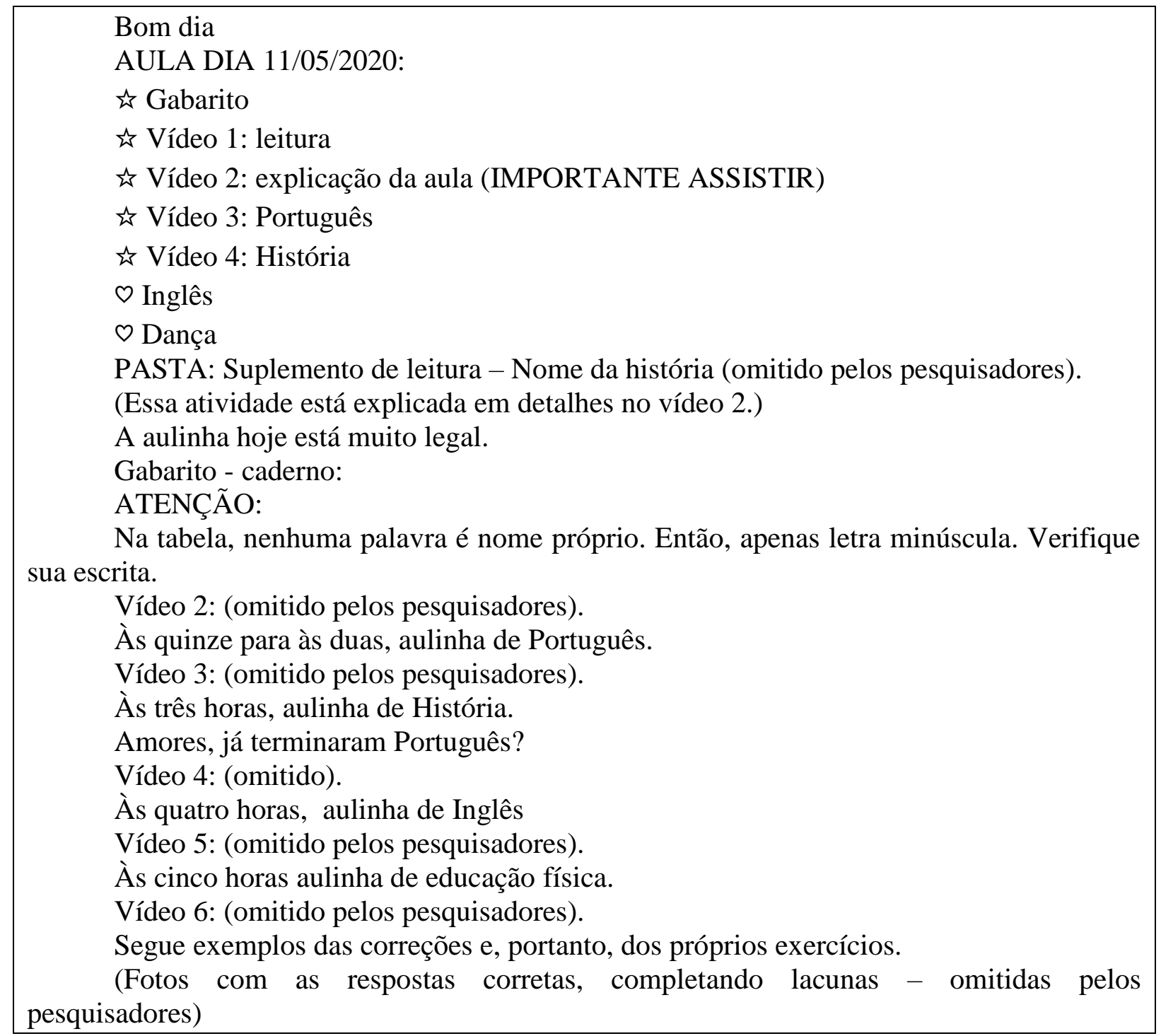

Quadro 1: Atividades solicitadas aos alunos do $4^{\circ}$ ano por aplicativo de mensagem

Fonte: Dados organizados pelas autoras, com base em uma "aula remota" de $4^{\circ}$ ano do Fundamental I. 
A proposta aqui não é descaracterizar a prática pedagógica realizada no contexto de pandemia, mas analisar algumas características desse modelo pedagógico (que poderia ser desenvolvido presencial ou remotamente). Essa proposta remete a uma prática de explicação oral e execução de exercícios escritos. Diante desse exemplo, podemos questionar: como desenvolver um ambiente autônomo, de cooperação e de estímulo da criatividade?

Pimenta e Almeida (2011) orientam sobre o ensino ocupar um local de destaque nas reflexões docentes acerca de suas perspectivas didáticas. Ensinar requer conhecimentos específicos e consolidados, porém requer também "atualização constante das abordagens dos conteúdos e das novas maneiras didática de ensiná-los" (PIMENTA; ALMEIDA, 2011, p. 28). Nesse sentido, observa-se que, na maioria das vezes, as práticas realizadas no ensino remoto apenas reproduziram práticas já consolidadas no ensino presencial de orientação tradicional. Destaca-se a necessidade da atualização dessas práticas estarem em diálogo com as necessidades de aprendizagem, incluindo os aspectos sociais, do público a que se destinam, destituindo-se de seus caráter "somente" protocolar.

Apesar da exemplificação de apenas um dos dias letivos, fez-se o acompanhamento de três meses das aulas remotas dessa professora e foi possível ter acesso aos vídeos da professora com as explicações dos conteúdos, que não passavam de vídeos de leitura dos capítulos teóricos, em alguns deles havia também a leitura dos exercícios a serem executados, porém raramente se explicava os mesmos contextualizando as respostas. Em alguns vídeos se trazia a explicação como se fosse no quadro negro, com relação ao conteúdo de cálculos matemáticos (adição, subtração, divisão e multiplicação).

No que se refere ao relato da professora às pesquisadoras, sobre esse momento profissional ao qual está vivenciando, houve um desabafo com relação a realização e execução das gravações das aulas e suas dificuldades com relação ao manuseio dos recursos tecnológicos e ainda com o fluxo contínuo e exagerado de trabalho. O que respalda as questões tratadas anteriormente acerca da precarização do trabalho docente.

Obviamente que esse é apenas um excerto da prática dessa professora e ele contribui para reflexão da temática na esperança de promover processos de tomada de consciência que levem os professores/as à construção de uma identidade pautada na promoção do desenvolvimento dos alunos, como indica Paganini-da-Silva (2015), e não apenas no cumprimento dos aspectos burocráticos do ensino. 
Destacando a perspectiva da autonomia é importante considerar que:

$\mathrm{Na}$ comunidade, as regras e todo o trabalho devem ser formulados pelos seus membros; portanto, crianças e professoras têm papel fundamental haja vista que a disciplina é orientada pelo respeito, e não, pela obediência cega. $O$ professor é autoridade, sabe onde quer chegar, porém, dá oportunidades para que a criança cresça em suas responsabilidades e participação efetiva" (TOGNETA, 2001, p. 05).

Cabe ponderar que a autonomia pretendida com alunos, não é possível de ser obtida sem a intervenção presencial do professor, não diz respeito a autonomia do "deixar fazer sozinho e como bem desejar", se refere ao que Jean Piaget (1994) chama de "Self governament”, ações que levem ao respeito mútuo, o mesmo autor ressalta que:

O respeito mútuo aparece, portanto, como a condição necessária da autonomia, sob seu duplo aspecto intelectual e moral. Do ponto de vista intelectual, liberta as crianças das opiniões impostas, em proveito da coerência interna e do controle recíproco. Do ponto de vista moral, substitui as normas da autoridade pela norma imanente à própria ação e à própria consciência, que é a reciprocidade na simpatia (PIAGET, 1994, p. 91).

Pode-se inferir, a partir desse exemplo, que o ensino remoto não é favorável para promover essa autonomia tendo em vista suas características e uma vez que este desconsidera elementos básicos para essa etapa da vida das crianças. Entretanto, é sabido que o ensino presencial mantido ao longo do tempo nas escolas, pautado em uma metodologia tradicional, também não é o mais adequado.

Frente ao exposto, enfatiza-se que o ensino remoto não é plausível de gerar processos de ensino-aprendizagem consideráveis para todas as crianças, sejam da Educação Infantil e/ou Ensino Fundamental. Tal processo desconsidera as interações professores/as-estudantes e especialmente entre os estudantes e seus pares. Nessa faixa etária a interação é condição sine qua non para uma boa aprendizagem.

Há que se considerar que as inquietações e necessidades infantis referente ao desenvolvimento bem como sua essência de interação e criação é deixada de lado quando solicita-se a essa criança que apenas execute os exercícios após a "vídeo-aula", que não passa de uma leitura, sendo todo esse processo executado ou por ela sozinha ou, às vezes, com o auxílio de um adulto que não tem preparação adequada para as explicações orais e muito menos das relações dialógicas de um processo cooperativo.

Revista Devir Educação, Lavras-MG. Edição Especial, p.409-429, Set./2021. 
Percebe-se como assevera Alves (2020, p.361):

[...] as práticas docentes que vem sendo realizadas reproduzem o que tem de pior nas aulas presenciais, utilizando um modelo de interação broadcasting, no qual os professores transmitem informações e orientações para um grupo de alunos que nem sempre consegue acompanhar o que está acontecendo nesses encontros virtuais e participar. Esse é um clássico exemplo de uma perspectiva instrumental da tecnologia.

E ressalta ainda: "[...] o que deveria ser prazeroso e rico, torna-se estressante, desgastante e frustrante para os sujeitos do processo de ensinar e aprender, incluindo nessa situação singular, os seus pais" (ALVES, 2020, p. 360).

No formato que a escola é pensada e organizada atualmente ela acaba por permitir lacunas em sua constituição considerando como principal indicador o ensino. Assim também se faz o ensino remoto. A reflexão traçada aqui pretende como objetivo final que o modelo escolar padrão possa ser repensado, superado, que o acúmulo de conteúdos, das aulas como transmissão desses conteúdos e as avaliações baseadas em provas deixem de ser o fim último da educação escolar. Sobretudo, que a escola passe a ter o indicador de ensino e aprendizagem como elemento primordial de suas práticas.

Uma das questões próprias a esse momento é até que ponto o sistema escolar, os professores/as, os pais e a comunidade se preocupam com uma aprendizagem significativa ou apenas com o cumprimento de metas e estratégias estabelecidas anteriormente.

Portanto, sugere-se três aspectos primordiais a serem considerados respaldados por Togneta (2001) e Paganini-da-Silva (2015):

a) Que as relações na escola promovam um ambiente sócio moral, com predomínio de processos de respeito mútuo e reciprocidade entre os estudantes.

b) Que as práticas docentes sejam sustentadas por práticas cooperativas e com a finalidade de promover a aprendizagem mais do que apenas ensinar (no formato de transmissão oral pura e simples), com ressignificação desse conceito;

c) Que haja uma tomada de consciência por parte dos docentes a respeito de sua identidade profissional, se reconhecendo como pertencentes a um grupo de profissionais específico que supere a ideia do professor transmissor e que possui um "dom" para a docência. É imprescindível valorizar a ideia da docência como um trabalho atrelado a uma constituição histórica, com especificidades, que requer habilidades e competências, assim como aspectos subjetivos que promovem sua constituição identitária. 


\section{Considerações Finais}

Esse artigo objetivou problematizar e refletir sobre a necessidade de analisar o modelo escolar baseado no acúmulo de conteúdo (visão conteudista) e, como esse modelo aparece significado ou ressignificado frente a pandemia de Covid-19.

Para tanto, apresentou-se de forma breve alguns conceitos de $\mathrm{EaD}$ e o que vem sendo desenvolvido durante o período de distanciamento social. Discutiu-se aspectos relevantes sobre a profissão docente, sua especificidade, bem como a precarização do trabalho docente na atualidade e levantou-se alguns aspectos relativos ao reconhecimento da infância e, ainda, a problematização acerca do modelo escolar e suas necessidades de superação.

Como ressaltado anteriormente, a intenção não é desqualificar os esforços neste período, mas que seus acertos e erros e/ou limitações sejam revistos, para uma possível promoção da educação escolar capaz de lidar com a mudança recorrente e com as incertezas postas por um mundo globalizado.

Por fim destaca-se que os elementos problematizados nesse artigo, almejam que a profissão docente seja valorizada como deve ser: uma profissão responsável pela formação de pessoas, que seus profissionais consigam realizar suas práticas de forma mais livre, que os espaços escolares possam ser redefinidos e que os momentos de formação docente não sejam somente dedicados a como transmitir os conteúdos, mas que a formação consiga conectá-los com os contextos sociais e políticos vigentes, promotores de aprendizagens.

Encerra-se esse texto evidenciando que tais considerações sobre a educação remota e a educação presencial tragam perspectiva de mudança. Se por um lado a EaD é comprometida e impossível de ser implantada, com tantas desigualdades sociais e limitações para essa faixa etária, especialmente quando ela não é considerada em sua constituição teórica, já que o que assistimos com as escolas foi a execução do ensino remoto, por outro lado a escola presencial também apresenta dificuldades em sua organização física, curricular, metodológica, política e social, promovendo um modelo de ensino que comtempla um desconsiderar do humano, da 
infância, bem como da profissão docente que é arrastado por mais de um século sem ser vencido.

Nesse sentido, a pandemia de Covid-19 oportuniza um repensar, pois escancara que a escola está centrada em um modelo que já não responde as demandas de seu tempo histórico. Um repensar do modelo escolar baseado no acúmulo de conteúdo, que dê lugar aos professores/as na especificidade e complexidade de sua profissão. É urgente e preciso que a escola se transforme para que as crianças tenham possibilidade de desenvolver-se autônoma e criativamente podendo transformar o mundo e suas relações ainda tão perversas.

\section{REFERÊNCIAS}

ADORNO, T. Educação e emancipação. São Paulo: Paz e Terra, 2003.

ALMEIDA, Maria Elizabeth Bianconcini de. Educação a distância na internet: abordagens e contribuições dos ambientes digitais de aprendizagem. Educação e Pesquisa, São Paulo, v. 29, n. 2, p. 327-340, jul/dez.2003. access on 25 Nov. 2020. http://dx.doi.org/10.1590/S1517$\underline{97022003000200010 .}$.

ALVES, Lucineia. Educação a distância: conceitos e história no Brasil e no mundo. Associação Brasileira de Educação a Distância (RBAAD), vol. 10, p. 83-92. 2011. DOI: https://doi.org/10.17143/rbaad.v10i0.235

ALVES, Lynn. Educação remota: entre a ilusão e a realidade. In: Interfaces Científicas, Aracaju, V.8, N.3, p. 348 - 365 - 2020. DOI: https://doi.org/10.17564/2316$\underline{3828.2020 \mathrm{v} 8 \mathrm{n} 3 \mathrm{p} 348-365}$

ARROYO, Miguel Gonzalez. Corpos precarizados que interrogam nossa ética profissional. In: ARROYO, Miguel González; SILVA Maurício Roberto da. (orgs). Corpo Infância: exercícios tensos de ser criança; por outras pedagogias. Petrópolis, RJ: Vozes, 2012b. p. 2354.

, Outros sujeitos, outras pedagogias. Petrópolis, RJ: Vozes, 2012a.

A Infância interroga a pedagogia. In: SARMENTO, Manuel Jacinto. GOUVEA, Maria Cristina de Soares. Estudos da Infância: educação práticas sociais. Rio de Janeiro: Vozes, 2008, p. 119-140.

BOTO, Carlota. O desencantamento da criança: entre a Renascença e o Século das Luzes. In: FREITAS, Marcos Cézar. de; KUHLMANN JUNIOR, Moysés. (orgs). Os intelectuais na história da infância. São Paulo: Cortez, 2002. p. 11-60.

BRASIL. Ministério de Educação e Cultura. LDB - Lei no 9394/96, de 20 de dezembro de 1996. Estabelece as diretrizes e bases da Educação Nacional. Brasília: MEC, 1996. Acesso em: 10/06/2020, disponível em: http://www.planalto.gov.br/ccivil_03/leis/19394.htm 
BRASIL. Câmara dos Deputados. Decreto no5.622, de 19 de dezembro de 2005. Estabelece as diretrizes e bases da Educação Nacional. Brasília, 2005. Acesso em: 10/06/2020, disponível em: https://www2.camara.leg.br/legin/fed/decret/2005/decreto-5622-19-dezembro2005-539654-normaatualizada-pe.html

CHADDERTON, Charlotte; TORRANCE, Harry. Estudo de casos. In: SOMEKH, Bridget; LEWIN, Cathy. Teorias e Métodos de Pesquisa Social. Petrópolis, RJ. Vozes, 2015.

ESPANHA autoriza passeios com crianças durante isolamento para conter expansão do coronavírus. G1, digital, 26/04/2020. Seção Mundo, notícia. Disponível em: https://g1.globo.com/mundo/noticia/2020/04/26/espanha-autoriza-passeios-com-criancasdurante-isolamento-para-conter-expansao-do-coronavirus.ghtml. Acesso em 13/05/2020.

FREIRE, Paulo. Pedagogia da Autonomia: Saberes necessários à prática educativa. 21. ed. Rio de Janeiro: Paz e Terra, 1996.

FREIRE, Paulo. Professora sim, tia não. 19ed. São Paulo: Cortez, 2008.

FREUD, Sigmund. O Mal-Estar na civilização. Tradução de José Octávio de Aguiar Abreu. Rio de Janeiro: Imago Ed. 1997.

IMBERNÓN, Francisco. La formación y el desarrollo profesional del profesorado: hacia una nueva cultura profesional. Barcelona: Graó, 1994. 163p.

IMBÉRNON, Francisco. Formação docente e profissional: formar-se para a mudança e a incerteza. São Paulo: Cortez, 2004.

Qualidade do ensino e formação do professorado: uma mudança necessária. São Paulo: Cortez, 2016.

KUHLMANN JUNIOR, Moysés. Infância e educação infantil: uma abordagem histórica. 4ed. Porto Alegre: Mediação, 2007.

MIZUKAMI, Maria da Graça Nicoletti. Ensino: as abordagens do Processo. 1. ed. São Paulo: EPU, 1986. 120p.

MÜLLER, Verônica Regina. História de crianças e infâncias: registros, narrativas e vida privada. Rio de Janeiro: Vozes, 2007.

NÓVOA, António. Firmar a posição como professor, afirmar a profissão docente. Cadernos de Pesquisa. V.47; n. 166, p. 1106-1133, out./dez. 2017.

NÓVOA, António. Professores: Imagens do futuro presente. Educa. Lisboa, 2009. 95p. Disponível em: https://rosaurasoligo.files.wordpress.com/2017/04/antc3b3nio-nc3b3voaprofessores-imagens-do-futuro-presente.pdf. Acesso em: 13 maio. 2020, 24:31:05. 
PAGANINI-DA-SILVA, E. Ser professor e a relação ensino-aprendizagem: uma contribuição piagetiana. 2015. 234p. Tese (Doutorado em Educação) - Universidade Estadual Paulista. Marília, São Paulo.

PELOSO, F. C. Infâncias do e no campo: um retrato dos estudos pedagógicos nacionais. 2015. 223 p. Tese. (Doutorado em Educação) - Universidade Federal de São Carlos, São Paulo.

PIAGET, J. Para onde vai a educação? Tradução Ivette Braga. 21.ed. Editora José Olympio: Rio de Janeiro, 2011.

PIAGET, J. O Juízo Moral na criança. Tradução: Elzon Lenardon. São Paulo: Summus, [1912] 1994. 302p.

PIMENTA, S. G.; ALMEIDA, M. I. (Orgs.). Pedagogia Universitária: caminhos para a formação de professores. São Paulo: Cortez, 2011.

TARDIF, Maurice; LESSARD, Claude. O trabalho docente: elementos para uma teoria da docência como profissão de interações humanas. Editora Vozes, 9a edição, 2014.

RODRIGUES, Cleide Aparecida Carvalho. Configurações das abordagens pedagógicas da educação a distância. Associação Brasileira de Educação a Distância (RBAAD), vol. 10, p. 72-82. 2011.

SANTOS, Boaventura de Sousa. A Cruel Pedagogia do Vírus. Editora: Edições Almedina, Portugal, 2020.

SARMENTO, Manuel Jacinto. Sociologia da Infância: correntes e confluências. In: SARMENTO, Manuel Jacinto. GOUVEA, Maria Cristina Soares de. (orgs). Estudos da Infância: educação e práticas sociais. Rio de Janeiro: Vozes, 2008, p. 17-39.

Visibilidade social e estudo da infância. VASCONCELLOS, Vera Maria Ramos de; SARMENTO, Manuel Jaciento. Infância (in)visível. Araraquara: Junqueira e Marin, 2007. p. 25-49.

As culturas da infância nas encruzilhadas da segunda modernidade. In: SARMENTO, Manuel Jacinto; CERISARA, Ana Beatriz (org). Crianças e Miúdos: perspectivas sociopedagógicas. Porto Asa, 2003, p. 09-34.

SINGER, H. República de crianças: sobre experiências de resistência. Campinas, SP: Mercado de Letras, 2010.

TOGNETTA, L. R. P. A dinâmica de um ambiente cooperativo. Anais do XVIII Encontro Nacional de Professores do PROEPRE: "Transformar a educação: Nosso Desafio". Campinas, SP: Faculdade de Educação, Unicamp, 2001, p. 165-173. 
VASCONCELOS, S. P. G. Educação a Distância: histórico e perspectivas. Universidade do Estado do Rio de Janeiro (UERJ), 2010. Acesso em: 08 jan. 2020. Disponível em: http://www.filologia.org.br/viiifelin/19.htm

WINNICOTT, Donald. Woods. O brincar e a realidade. Trad. de José Octávio de Aguiar Abreu e Vanede Nobre. Rio de Janeiro, Imago, 1975.

Recebido em: 22/07/21

Aprovado em: 10/09/21

Revista Devir Educação, Lavras-MG. Edição Especial, p.409-429, Set./2021. 